\title{
Fluctuations at electrode-YSZ interfaces
}

\author{
Jacobsen, Torben; Hansen, Karin Vels; Skou, Eivind
}

Published in:

Journal of The Electrochemical Society

Link to article, DOI:

10.1149/1.2060667

Publication date:

2005

Document Version

Publisher's PDF, also known as Version of record

Link back to DTU Orbit

Citation (APA):

Jacobsen, T., Hansen, K. V., \& Skou, E. (2005). Fluctuations at electrode-YSZ interfaces. Journal of The Electrochemical Society, 152(11), A2203-2206. https://doi.org/10.1149/1.2060667

\section{General rights}

Copyright and moral rights for the publications made accessible in the public portal are retained by the authors and/or other copyright owners and it is a condition of accessing publications that users recognise and abide by the legal requirements associated with these rights.

- Users may download and print one copy of any publication from the public portal for the purpose of private study or research.

- You may not further distribute the material or use it for any profit-making activity or commercial gain

- You may freely distribute the URL identifying the publication in the public portal

If you believe that this document breaches copyright please contact us providing details, and we will remove access to the work immediately and investigate your claim. 


\title{
Fluctuations at Electrode-YSZ Interfaces
}

\author{
T. Jacobsen, ${ }^{\mathrm{a}, *, \mathrm{z}}$ K. Vels Hansen, ${ }^{\mathrm{b}}$ and E. Skou ${ }^{\mathrm{c}, *}$ \\ ${ }^{a}$ Department of Chemistry, Technical University of Denmark, DK-2800 Lyngby, Denmark \\ ${ }^{b}$ Department of Materials Research, Ris $\phi$ National Laboratory, DK-4000 Roskilde, Denmark \\ ${ }^{c}$ Department of Chemistry, University of Southern Denmark, DK-5230 Odense M, Denmark
}

Current fluctuations at potentiostatically controlled point electrodes of $\mathrm{Pt}, \mathrm{La}_{0.85} \mathrm{Sr}_{0.15} \mathrm{MnO}_{3}$ (LSM), and Ni on yttria-stabilized zirconia (YSZ) surfaces are determined at $1000^{\circ} \mathrm{C}$. For the oxygen reduction process on Pt electrodes, characteristic sawtoothshaped, low-frequency fluctuations are observed. At temperatures below $900^{\circ} \mathrm{C}$ the fluctuations cease. At LSM oxygen electrodes and $\mathrm{Ni}$ hydrogen electrodes the fluctuations are similar in amplitude and frequency, but the characteristic shape is not observed. Also some spectacular, but not easily reproduced, observations on Ni electrodes in hydrogen/water atmosphere are presented for discussion. The origin of the observations is not known at present, but it appears likely that they are related to the activation/ deactivation mechanism of solid oxide fuel cells.

(C) 2005 The Electrochemical Society. [DOI: 10.1149/1.2060667] All rights reserved.

Manuscript submitted April 1, 2005; revised manuscript received July 15, 2005. Available electronically September 30, 2005.

From experiments on electrodes contacted to yttria-stabilized zirconia (YSZ) surfaces it is well known that continuous polarization or even a short current/overvoltage pulse can decrease interfacial impedance, leading to a temporary increase in performance. ${ }^{1,2}$ Linear sweep voltammetry (LSV) has shown inductive loops even with amplitudes as low as $\pm 25 \mathrm{mV}$, which would normally be considered safely inside the linear regime at $1000^{\circ} \mathrm{C}$, and a nonlinear behavior is seen. ${ }^{3}$ Common to these studies is that they show an increased performance during polarization followed by inactivation when the electrode is relaxed at lower polarization.

Atomic force microscopy (AFM) studies have shown that the microstructure at the electrode-electrolyte interface is changed during polarization, ${ }^{4,5}$ and impurities as well as YSZ material are transported by the current; below anodically polarized Pt electrodes a porous YSZ structure is formed. Although these phenomena are not fully understood at present, it seems likely that they are related and that they are of importance for the long-term stability of solid oxide fuel cells (SOFCs).

The basic idea of the present work is that changes in the morphology of the triple-phase boundary may be discrete in the sense that channels along the electrode-electrolyte interface may suddenly be blocked or opened for transport of reactants. Such effects would be reflected as fluctuations in the current of an electrode at controlled potential.

\section{Theory}

When charged particles are exchanged across an interface or energy barrier, the distribution of charge between the double layers on each side of the barrier fluctuates in time. For an isolated system the result is a fluctuating potential difference across the interface. In the case where the potential across the interface is controlled by an external source (potentiostat), a fluctuating current is observed. If the charge transfer is determined by thermal activation only, the power spectrum, $S_{i}(\omega)$, of noise current is given by ${ }^{7}$

$$
S_{i}(\omega)=2 k \operatorname{RRe}[Y(j \omega)]
$$

where $\operatorname{Re}[Y(j \omega)]$ is the real part of the electrode admittance. Taking a low-frequency admittance value of $1 \mathrm{mS}$ the resulting value of the power spectrum is $3.5 \times 10^{-23} \mathrm{~A}^{2}$ at $1000^{\circ} \mathrm{C}$, i.e., thermal noise is not significant when compared to the current noise observed in the present work at low frequencies.

For a potentiostatically controlled solid-state gas electrode, the current is determined by the length of the triple-phase boundary (TPB), $l_{\mathrm{TPB}}$, the overvoltage, $\eta$, and the dc admittance per unit length of the TPB, $Y_{\circ}$. Within the linear range the current can be written as

\footnotetext{
* Electrochemical Society Active Member

z E-mail: tj@kemi.dtu.dk
}

$$
i=Y_{\mathrm{o}} l_{\mathrm{TPB}} \eta
$$

Assuming that the overvoltage contains a low-frequency noise component, $\delta \eta$, the corresponding noise current is

$$
\delta i=Y_{\mathrm{o}} l_{\mathrm{TPB}} \delta \eta
$$

Also, changes in the properties of the reaction zone influence the current. For metal electrodes the morphology of the electrodeelectrolyte interface and probably the TPB length is known to change when polarized. ${ }^{4,5}$ In the case of ceramic nonstoichiometric electrode materials, like $\mathrm{La}_{0.85} \mathrm{Sr}_{0.15} \mathrm{MnO}_{3}$ (LSM), the oxygen stoichiometry changes with the electrode potential. Thus, the catalytic activity and consequently the admittance per unit length, $Y_{\circ}$, depends on the polarization, not only according to the Butler-Volmer equation, but it is also influenced by the changes in the stoichiometry of the electrode surface.

The combination of these effects can be described in terms of a change in the product of the unit length admittance and the length of the TPB, $\delta\left(Y_{\circ} l_{\mathrm{TPB}}\right)$, giving the current response

$$
\delta i=\eta \delta\left(Y_{\mathrm{o}} l_{\mathrm{TPB}}\right)
$$

or, after combination with Eq. 1

$$
\frac{\delta i}{i}=\frac{\delta\left(Y_{\mathrm{o}} l_{\mathrm{TPB}}\right)}{Y_{\mathrm{o}} l_{\mathrm{TPB}}}
$$

In the case of external noise sources as amplifier noise and induced transients, the current response is proportional to the noise in the signal source, i.e., applied voltage or current amplifier noise only. For fluctuations in the TPB length and unit length activity the current noise/current ratio is proportional to the fluctuations. Thus, it should be possible to discriminate between noise induced by fluctuations in the interfacial properties and noise due other sources.

\section{Experimental}

Experiments were carried out on Pt (sphere, diameter 0.5-1 mm), $\mathrm{La}_{0.85} \mathrm{Sr}_{0.15} \mathrm{MnO}_{3}$ (particle size $\sim 1 \mathrm{~mm}$ ), and $\mathrm{Ni}(0.5-\mathrm{mm}$ wire) electrodes. The electrode was mounted with an alumina tube and pressed against the polished YSZ electrolyte by the weight of the tube (5-15 g). The YSZ electrolyte was equipped with a painted Pt counter electrode. The setup is outlined in Fig. 1.
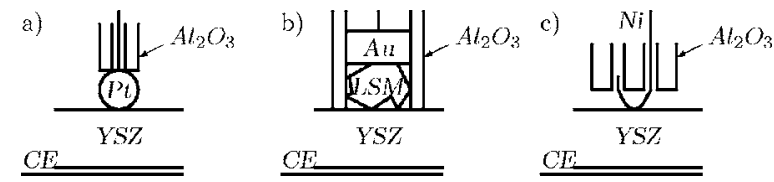

Figure 1. Experimental setup: (a) Pt sphere electrode, (b) LSM particle, and (c) Ni wire electrode. Pt painted counter electrode (CE). 


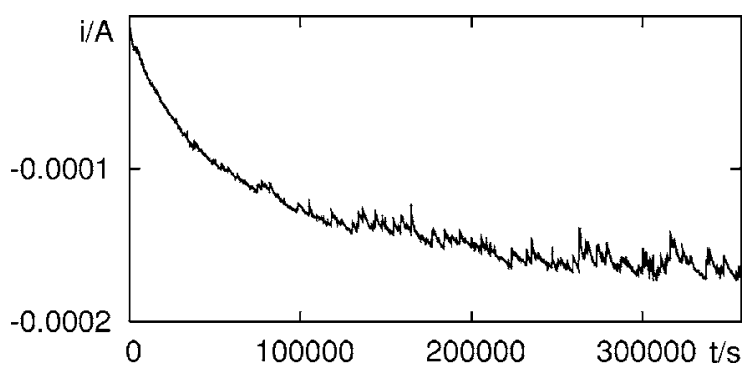

Figure 2. Current response to a $-0.1 \mathrm{~V}$ overvoltage applied to a Pt sphere at $1000^{\circ} \mathrm{C}$.

Except for the results shown in Fig. 11, the data collection as well as the driving signal for the potentiostat was generated by a PC-controlled HP75000 VXI system. To exclude transients from the $\mathrm{D} / \mathrm{A}$ converter steps (size $0.3 \mathrm{mV}$ ) from the driving signal to the potentiostat, a frequency modulation technique ${ }^{6}$ was used prior to smoothening in a 100-s low-pass filter and the potentiostats used were laboratory constructions. Normally data points were sampled every $10 \mathrm{~s}$. The linear temperature sweeps were controlled by programmable Eurotherm 902 regulators.

\section{Results}

As seen from Fig. 2, the initial response to the polarization of a $\mathrm{Pt}$ sphere after the temperature has stabilized at $1000^{\circ} \mathrm{C}$ has the character of an asymptotic increase in the cathodic current toward a stable value. This reflects the plastic deformation of the sphere increasing the contact area, as well as the activation of the electrode. It is noted that a fluctuating signal, which may at first look rather random, develops with time. A closer inspection reveals a characteristic pattern consisting of a rapid decrease in the current followed by a slow buildup.

To investigate the potential dependence of the current noise, LSV was applied to a Pt electrode. The result is shown in Fig. 3. In the first place the inductive loops caused by the activation mechanism in both the cathodic and the anodic direction are noted. Close to the equilibrium potential the current is a fairly smooth function of the potential, but at higher overvoltage (or current) an increasing noise signal is generated.

To inspect the fluctuations further, the anodic and the cathodic branches are approximated by second-order polynomials. These smoothening functions are subtracted from the experimental data, yielding the fluctuations in the current, $\Delta i$, shown in Fig. 4. It is seen that at high overvoltage the cathodic current contains the same saw-

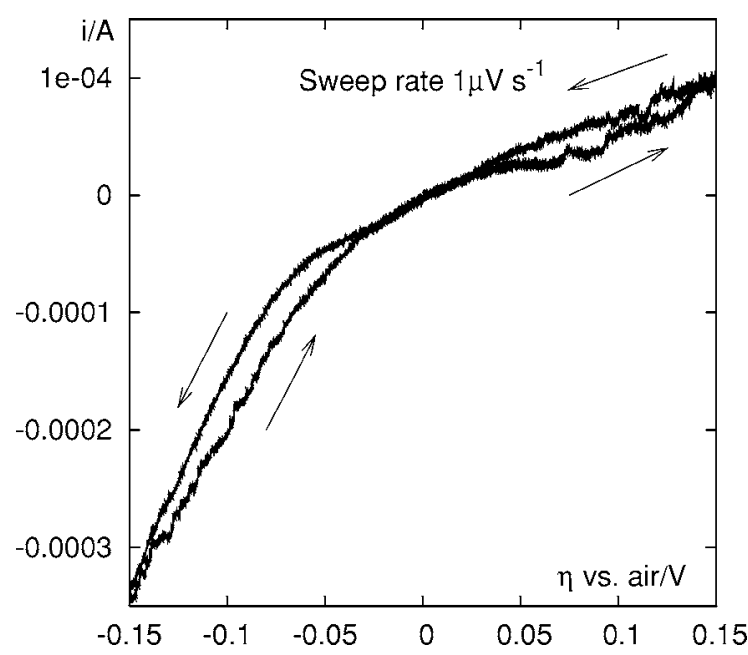

Figure 3. Potential sweep on a Pt sphere at $1000^{\circ} \mathrm{C}$. Sweep rate $1 \mu \mathrm{V} \mathrm{s}{ }^{-1}$.
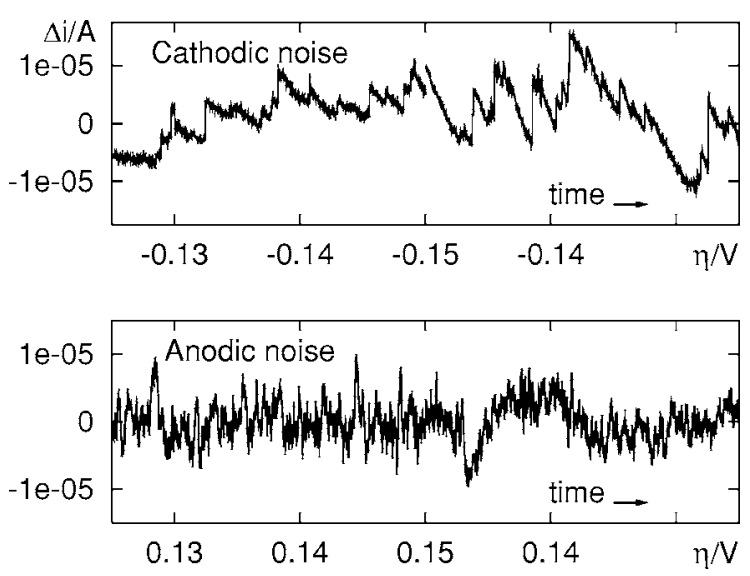

Figure 4. Current fluctuations at a Pt sphere in selected sections of a linear potential sweep $(0 \rightarrow-0.15 \rightarrow+0.15 \rightarrow 0 \mathrm{~V})$ in air at $1000^{\circ} \mathrm{C}$. Sweep rate $1 \mu \mathrm{V} \mathrm{s}^{-1}$.

tooth pattern as that observed for the potential step perturbation in Fig. 2. At high anodic overvoltage the fluctuations also increase, but now the behavior is more like a random noise signal.

From Fig. 4 it is seen that the sawtooth fluctuations are typically covering a few millivolts $\left(\sim 10^{3} \mathrm{~s}\right)$, i.e., corresponding to a frequency in the sub-millihertz region. Thus, a more accurate statistical analysis within a reasonable time window is not possible.

In Fig. 5 absolute fluctuations as well as fluctuations relative to the smoothed current, $\langle i\rangle$, are shown. As expected from Fig. 3, the amplitude is seen to increase with the polarization, or current. A qualitative comparison of the two plots shows that the normalized noise is more evenly distributed. Thus, the fluctuations are approximately proportional to the current. According to Eq. 4 a proportionality indicates that the noise is actually due to fluctuations in the properties of the active TPB. The sawtooth shape points toward a competition between two counteracting processes-a fast one decreasing the electrode activity and a slow current-driven process regenerating it. Probably these are the processes responsible for the general activation/deactivation mechanism of Pt electrodes. A somewhat speculative physical interpretation could be that the sudden descent of the current is caused by a blocking of a reaction channel along the interface by surface mobile impurities, and the slow, almost linear, increase in current represents the current-driven formation of a new channel.

The temperature dependence of the fluctuations was determined by linear temperature sweeps. As seen from Fig. 6 the amplitude and also the frequency decreases when the temperature is lowered, and at $900^{\circ} \mathrm{C}$ the fluctuations have almost ceased. Upon renewed heating

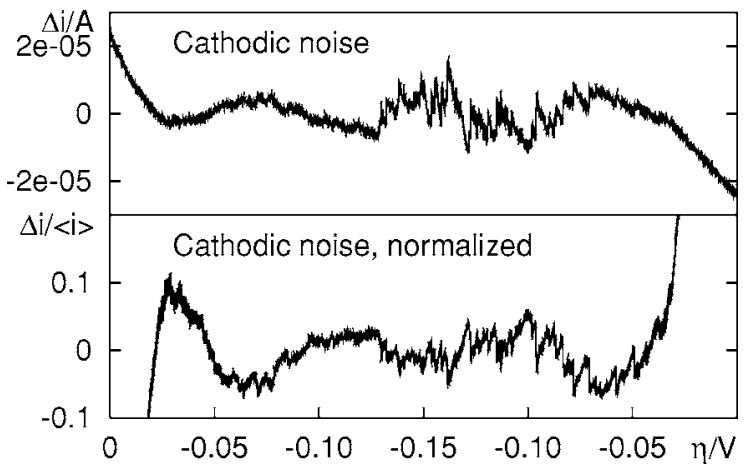

Figure 5. Absolute and normalized cathodic current fluctuations at the $\mathrm{Pt}$ sphere in the range $0 \rightarrow-0.15 \rightarrow 0 \mathrm{~V}$ of a linear potential sweep in air at $1000^{\circ} \mathrm{C}$. Sweep rate $1 \mu \mathrm{V} \mathrm{s}{ }^{-1}$. 

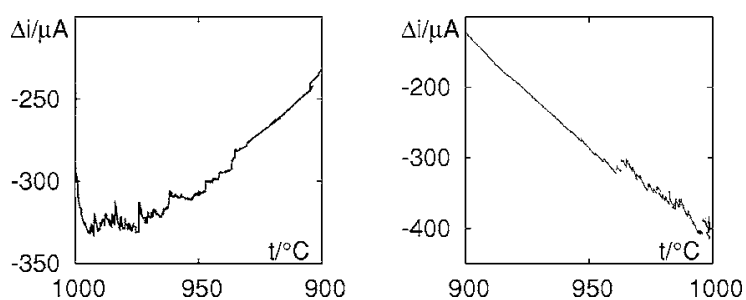

Figure 6. Linear temperature sweep from 1000 to $900^{\circ} \mathrm{C}$ and back. $\mathrm{Pt}$ sphere polarized to $-0.15 \mathrm{~V}$ in air. Sweep rate $2{ }^{\circ} \mathrm{C} / \mathrm{h}$. At $900^{\circ} \mathrm{C}$ the electrode was partially deactivated by not being polarized for $24 \mathrm{~h}$.

the noise is seen suddenly to return at $960^{\circ} \mathrm{C}$. Although the current is decreased by a factor of three, it is noted that the noise-to-current ratio is significantly lower at $900^{\circ} \mathrm{C}$. Thus, the change in the noise pattern is not a reflection of the temperature dependence of the current but the result of another temperature-dependent process influencing the electrode activity. The temperature effect is probably the most convincing evidence that the fluctuations are really due to the electrochemical system and not caused by external noise sources.

A similar investigation was performed on LSM. Figures 7 and 8 show the linear sweep behavior as well as the expanded noise-to-

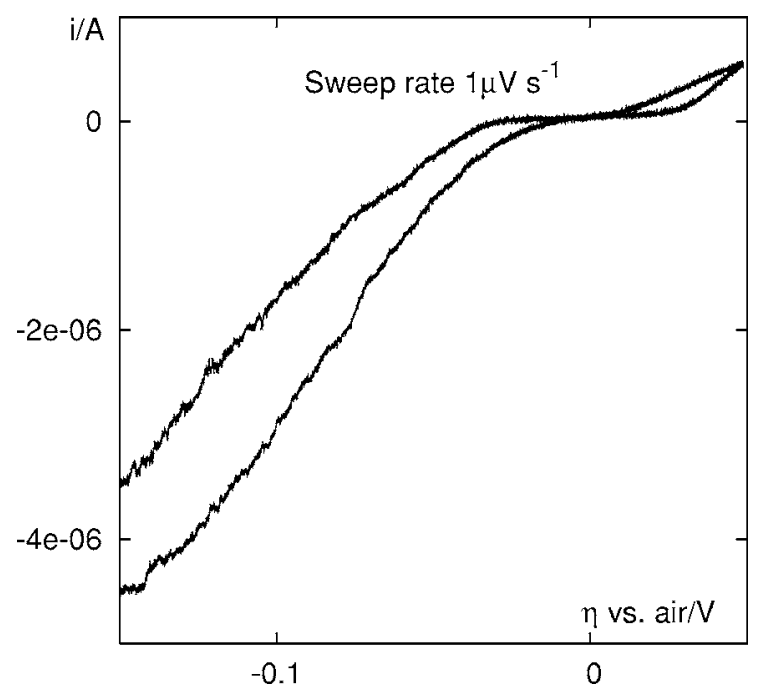

Figure 7. Potential sweep on an LSM particle in air at $1000^{\circ} \mathrm{C}$.
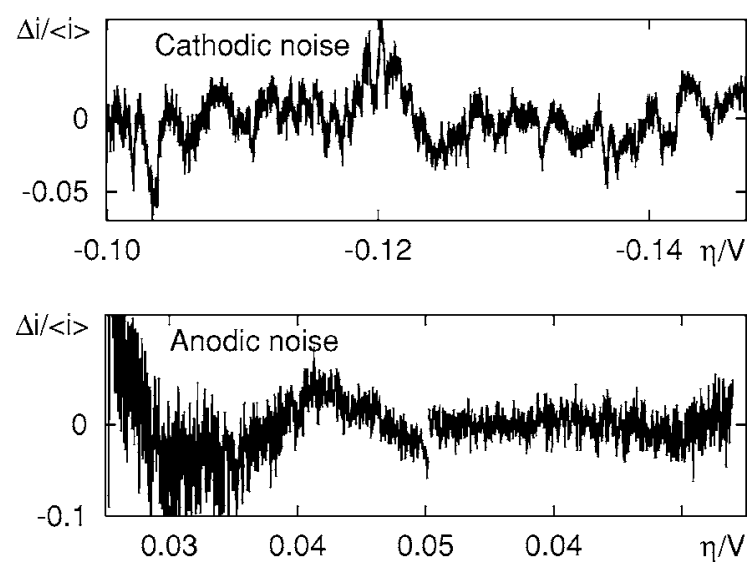

Figure 8. Relative current fluctuations in selected sections of a linear potential sweep $(-0.10 \rightarrow 0.050 \rightarrow-0.10 \mathrm{~V})$ on a LSM particle in air at $1000^{\circ} \mathrm{C}$. Sweep rate $1 \mu \mathrm{V} \mathrm{s}^{-1}$. To reduce random noise the anodic segment is the average of five samples $(\sim 50 \mathrm{~s})$.

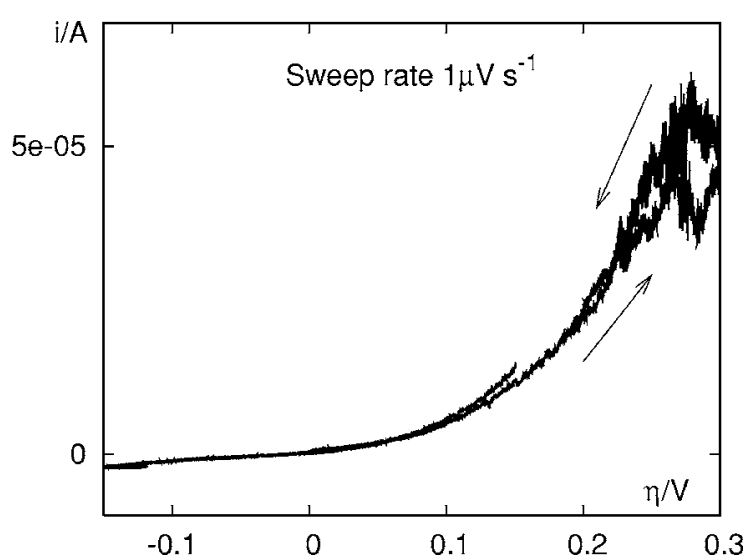

Figure 9. Potential sweep on a $\mathrm{Ni}$ wire electrode at $1000^{\circ} \mathrm{C}$. Atmosphere $7 \% \mathrm{H}_{2}+93 \%$ Ar saturated with water at room temperature. The discontinuity at $0.15 \mathrm{~V}$ is caused by a data capturing failure.

current ratio for cathodic and anodic sections of the sweep. Compared to the Pt sweep in Fig. 3 the LSM sweep is similar, except that the currents are almost two orders of magnitude lower, probably due to a smaller TPB. The expanded noise traces in Fig. 8 show that in
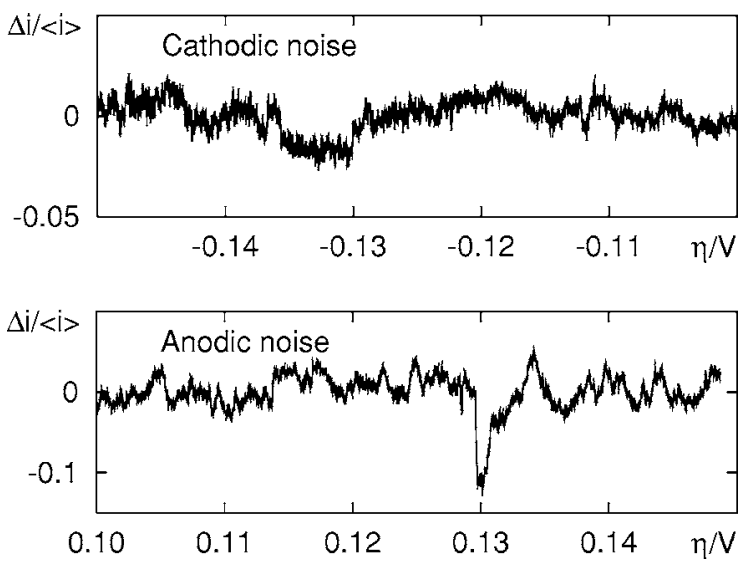

Figure 10. Relative current fluctuations in sections of a linear potential sweep $(0 \rightarrow-0.15 \rightarrow 0.30 \rightarrow 0.0 \mathrm{~V})$ on a $\mathrm{Ni}$ wire electrode at $1000^{\circ} \mathrm{C}$. Sweep rate $1 \mu \mathrm{V} \mathrm{s}^{-1}$. Atmosphere $7 \% \mathrm{H}_{2}+93 \%$ Ar saturated with water at room temperature. To reduce random noise the cathodic segment is the average of five current samples $(\sim 50 \mathrm{~s})$.

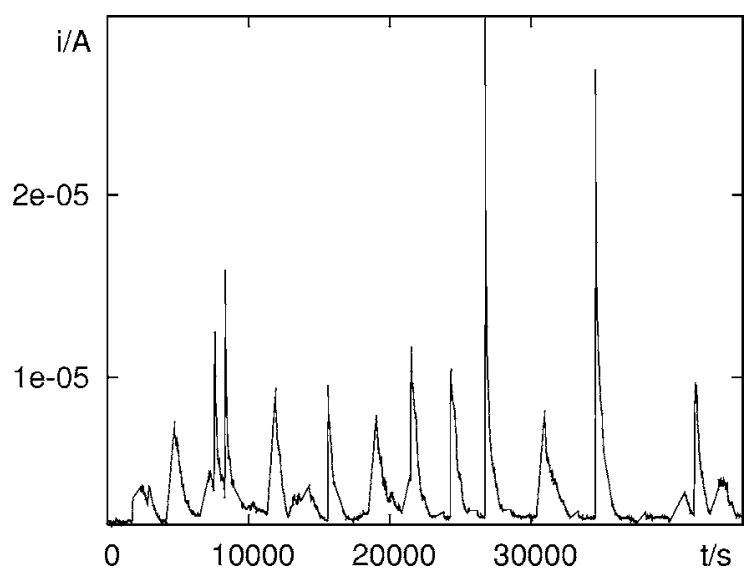

Figure 11. Ni wire electrode (purity $99.999 \%$ ) polarized to $0.1 \mathrm{~V}$ in a threeelectrode setup at $1000^{\circ} \mathrm{C}$. Atmosphere $97 \% \mathrm{H}_{2}+3 \% \mathrm{H}_{2} \mathrm{O}$. 
the cathodic range the noise frequency and relative amplitude are similar to those of the Pt electrodes, although the sawtooth pattern is not seen. In the anodic region the picture is more like random noise. Due to the lower anodic current used in the normalization, the relative contribution from other noise sources (random, $50 \mathrm{~Hz}$ from the furnace, etc.) contribute more to the LSM response.

Figure 9 shows a potential sweep for a Ni wire electrode. The current fluctuations normalized with smoothing second-order polynomial fits, $\langle i\rangle$, for both anodic and cathodic sections, are shown in Fig. 10. In the anodic direction the current fluctuations are clear, whereas the relative signal in the cathodic direction contains a large contribution of higher frequency random noise.

By far more spectacular than the results for the oxygen electrodes are the current spikes on the $\mathrm{Ni}$ electrodes polarized to a constant anodic potential seen in Fig. 11. This very regular behavior has been observed a number of times for different $\mathrm{Ni}$ electrodes in three-electrode setups controlled by a Solartron 1287 electrochemical interface and a Solartron 1250 frequency response analyzer. ${ }^{8}$ The graph shown was obtained after several days of polarization and after a number of impedance spectra had been determined. So far, attempts to reproduce the behavior on a twoelectrode setup with different instrumentation in another laboratory have not been successful. At present it cannot be ruled out that the peaks are induced by mechanical vibrations, electrical transients on the main supply, or other external sources. In any case, the effect is remarkable and the fact that the current is increased by an order of magnitude for a considerable period of time seems to justify further investigation.

\section{Conclusions}

The investigations have shown the noise patterns for the oxygen/ oxide reaction at Pt and LSM electrodes to be related. In the cathodic reactions low-frequency fluctuations are seen, whereas for the anodic reaction the behavior is more or less random. The sawtooth pattern seen appears specific for the Pt-YSZ interface. For the hydrogen electrode on Ni fluctuations are seen for both the anodic and the cathodic reactions.

The potential and temperature dependence of the results show that the fluctuations observed are created by the electrode reactions and not artifacts due to external noise sources.

Due to the limited fluctuation/random-noise ratio no definite conclusion can be drawn so far, but it seems safe to interpret the fluctuations as due to changes in the properties of the TPB.

The Technical University of Denmark assisted in meeting the publication costs of this article.

\section{References}

1. A. J. McEvoy, Solid State Ionics, 135, 331 (2000)

2. S. McIntosh, S. B. Adler, J. M. Vohs, and R. J. Gorte, Electrochem. Solid-State Lett., 7, A111 (2004)

3. T. Jacobsen, B. Zachau-Christiansen, L. Bay, and M. Juhl Jørgensen, Electrochim Acta, 46, 1019 (2001)

4. L. Bay and T. Jacobsen, Solid State Ionics, 93, 201 (1997).

5. K. Vels Jensen, S. Primdahl, I. Chorkendorff, and M. Mogensen, Solid State Ionics, 144, 197 (2001).

6. K. West, T. Jacobsen, B. Zachau-Christiansen, and S. Atlung, Electrochim. Acta, 28, 97 (1983).

7. A. Papoulis, Probability, Random Variables and Stochastic Processes, p. 364, McGraw-Hill, New York (1965).

8. K. Vels Hansen, K. Norrman, and M. Mogensen, J. Electrochem. Soc., 151, A1436 (2004). 